\title{
Las reglas para sentir "con" la Iglesia*
}

\author{
José Ignacio González Faus \\ San Cugat del Vallés, Barcelona \\ Centro de Reflexión Teológica, San Salvador
}

\section{Principios hermenéuticos}

Las mal llamadas reglas para sentir con la Iglesia suelen ser hoy piedra de tropiezo y de dificultad para algunos. Para entenderlas, me parece necesario atender a dos principios hermenéuticos fundamentales. Ignacio las escribe unos años después de concluidos los Ejercicios espirituales (EE), y las escribe con dos objetivos: no hacer daño al pueblo y no ser tachado de "luterano", como habían sido los alumbrados (una acusación que entonces funcionaba mágicamente, como en nuestros tiempos funcionó la de "comunista").

Teresa de Jesús vivió un ambiente similar: estaba segura de que la inquisición no tendría nada en su contra "y, si pensase había para qué", dice que ella misma "se la iría a buscar". Pero hubo de soportar también no sólo las acusaciones y etiquetas sino, sobre todo, las indecisiones de algunos confesores o censores que no acababan de entenderla, y que se vefan presionados y amenazados por gentes de esas que "han ofdo decir" o "saben de buena tinta"... Ignacio vive en este mismo ambiente que, por lo que toca a la práctica rastrera y antievangélica de la denuncia, todavía no ha desaparecido, en algunos sectores de la Iglesia. Sabe bien que se juega mucho en esto, y más en un momento en que estaba prohibido fundar nuevas órdenes y en que el drama de Lutero comenzaba a sacudir a la cristiandad.

* Este artículo constituye un capítulo de un libro del autor sobre los Ejercicios de san Ignacio, que aparecerd en 2007.

1. Vida 33,5 . 
El valor hermenéutico de estos objetivos se ve confirmado por el dato de que abre los ejercicios con una anotación, que podría parecer fuera de lugar, y más - aún por lo radical de su tono, pero que no es extemporánea, en el contexto descrito: "todo buen cristiano ha de ser más pronto a salvar la proposición del prójimo que a condenarla. Y si no la puede salvar inquira como la entiende..." (EE 22). Otra clave que, desgraciadamente, no ha perdido vigencia, en la Iglesia de hoy.

Pues bien, al primero de los objetivos señalados apuntan las reglas 1-12, redactadas en París. Tras ellas puede estar una acusación de La Sorbona contra Erasmo, que Ignacio debió conocer. Al segundo objetivo se encaminan de la 14 a la 18 y, tras ellas, parece estar un fraile agustino italiano, que acabó haciéndose luterano. Estas otras reglas parece que fueron redactadas cuando Ignacio ya estaba en Roma, gestionando la aprobación de la Compañía. Sobre la regla 13 no hay acuerdo.

Una palabra, pues, sobre cada una de estas dos claves.

\subsection{Atención a los sencillos}

San Ignacio no habla de sentir con la Iglesia, sino de reglas "para el sentido verdadero que en la Iglesia militante debemos tener" (EE 352). Este cambio de título me parece fundamental. Y creo que la sustitución del redactado original por la preposición "con" funciona interesadamente. "En la Iglesia" significa que habla desde dentro del pueblo de Dios y que no trata simplemente de sentir "con la jerarqufa". No establece, de ninguna manera, que el "sentido verdadero" es el de la jerarquía. Explica más bien cómo han de estar correctamente situados en la comunidad de fieles, aquellos que, por la razón que sea, resultan novedosos e injustamente sospechosos. En esa posición "recta" está implicada naturalmente una relación con la jerarquía, pero no es la única, como la jerarquía tampoco es la totalidad de la Iglesia.

Esta clave hermenéutica de atención al pueblo sencillo, que son hermanos nuestros en la fe, se mantiene y se ve confirmada por lo que dice en las últimas reglas cuando alude a la predestinación ${ }^{2}$ o a la justificación por la fe $o$ a las comparaciones entre santos: no hablar de tal manera que "el pueblo menudo... se descuide en las obras que conducen a la salud y provecho espiritual" (EE 367) o que "el pueblo en el obrar sea torpe y perezoso" (368). Los que tienen palabra en la Iglesia (teólogos, profesores, predicadores, jerarcas...) no la tienen para si solos, ni para sus colegas, sino principalmente para el pueblo. Estas reglas suelen desa-

2. En la regla 14, cuando escribe "dado que sea verdad que ninguno se puede salvar sin ser predestinado", hay una discusión sobre si debe leerse (en latin) "esser" o "sir" (corrección introducida más tarde por el P. Araoz y que no gustó a san Ignacio): en el primer tiempo del verbo hablaría de modo irreal: "aunque fuese...". El segundo tiene un sentido más real: "aunque sea"... 
tenderse hoy, como menos importantes, porque esos no son nuestros problemas. Sin embargo, no cabe prescindir de ellas como clave para entender lo que Ignacio busca evitar, en todo este apéndice: "que en tiempos tan peligrosos, las obras y el libre arbitrio reciban detrimento o por nada se tengan" (EE 369).

Desde un punto de vista pedagógico para nosotros, creo que puede ayudamos a entender el afán de estas reglas una comparación con el interés que se dio en la teología de la liberación por la religiosidad popular, tras los primeros momentos. Otra cosa muy distinta será si a veces la jerarquía utiliza la religiosidad popular no para purificarla desde dentro, sino en provecho de su resistencia a cambios que Dios parece pedirle ${ }^{3}$.

Desde esta clave hermenéutica, es legítimo preguntarse no sólo qué dijo, sino sobre todo qué diría hoy san Ignacio, en una sociedad que ya no es de cristiandad, sino laica, donde las fracturas no están fuera, sino dentro, y la publicidad de los pecados de la Iglesia, así como las críticas, son cosas de cada día y donde, como ha notado J. B. Metz, la religiosidad popular, aunque a veces nos parezca supersticiosa, es con frecuencia menos peligrosa para la fe que "la religión burguesa".

Hay un texto biblico que es uno de mis preferidos y que podría enmarcar lo que acabo de exponer. Me refiero al capítulo 14 de la Carta a los Romanos que es una especie de manifiesto de la tolerancia cristiana y que comienza: "al que es débil en la fe denle una buena acogida sin meterse a dar fallos sobre modos de pensar". Entonces separaban a los cristianos dudas estúpidas sobre la licitud de todos los alimentos, o existencia de días privilegiados. Resabios de tradiciones antiguas de las que no es fácil desprenderse y que pueden asimilarse a las obsesiones (por ejemplo, de gentes del Opus) por si comulgar en la boca y no en la mano etc. Pablo era un "ilustrado", en este sentido, y estaba liberado de manías absurdas que, a veces, pretenden dar a Dios un homenaje que no es el que Él quiere. Pero aun así, Pablo no da un fallo a favor de una u otra de esas prácticas en litigio. Se limita a decir: no juzgues a tu hermano, que él ya tiene un Señor que le juzga. Un precepto sumamente valorado para el apóstol como norma de acción para la gente creyente (recordemos cómo lo usa en todo el capítulo 2 de esta misma carta, contra los judlos).

El fundamento de este precepto es que sólo Dios mira los corazones, como decla el Antiguo Testamento, mientras que los hombres sólo vemos lo exterior. Bajo una práctica menos moderna o menos ilustrada puede haber un corazón de fe más pura (y viceversa). También Jesús se acomodó a religiosidades bastante infantiles: admiró la gran fe de la hemorroísa y no se entretuvo a decirle antes que era una ignorante, por creer que era preciso "tocarle" para obtener lo que ne-

3. Lo mismo que suelen hacer los políticos conservadores con el voto de los más sencillos. 
cesitaba... No querrá decir esto que no haya que luchar por ilustrar y modemizar la fe. Pero, como siempre, hay que hacerlo desde dentro de esa misma "religiosidad, y no como imposición o condena exterior. Y si, para ello, hay que comenzar "alabando candelas", pues comencemos por ahí. Pablo es aquí un ejemplo de ese "recto sentir", en la Iglesia militante.

\subsection{Evitar problemas inútiles o secundarios}

Respecto a la segunda clave hermenéutica, a partir de la regla 2, propone Ignacio una serie de prácticas que deben ser "alabadas": la confesión, la misa frecuente, las ordenes religiosas y los votos, las reliquias e indulgencias, los ayunos y abstinencias... Son todas ellas cosas criticadas de mil formas por Lutero (aún más que por Erasmo, quien lo que pretendía era dar razón a Lutero, en lo que la tuviera). Juan de la Cruz, en cambio (que no estaba obsesionado porque le acusasen de luterano), es bastante crítico con las "candelas" y demás, pero no desde el afán intelectual por una fe ilustrada, sino desde una experiencia mística, que siente que no es ése camino para acceder a Dios (olvidando quizá que la gente más sencilla puede necesitar ese tipo de caminos más sensibles).

\section{3. ¿Y hoy?}

Estas dos claves pueden resumirse en una sola: los contextos han cambiado. Melecio Agúndez, introduciendo el decreto sobre la Compañla y la Iglesia, de la Congregación General 34 (en 1994), reconoce que "la Iglesia no se reconoce ya a sí misma del mismo modo, ni con las mismas imágenes que en época de Ignacio y eso no puede no afectarnos". El mismo decreto citado afirma sin ambages que "el contexto en que Ignacio escribio estas reglas ha dejado de tener relevancia" (n. 16). Ha cambiado, pues, el contexto sociocultural y también el contexto eclesial. Y este decreto describe así este último cambio:

La renovación eclesiológica del concilio Vaticano II nos ha ayudado a redescubrir la Iglesia universal como una koinonia (comunión) de iglesias locales bajo el colegio episcopal, cuya cabeza es el obispo de Roma. Esto, a su vez, ha renovado nuestra conciencia del papel distintivo e inalienable del laicado en la vida de la Iglesia ${ }^{4}$. ¿Podemos sorprendernos de que esta conciencia más sentida de la corresponsabilidad de todo el pueblo de Dios en la vida toda de la Iglesia haya hecho aflorar un mayor número de voces y que no todas digan lo mismo? Esta es una fuente de vitalidad, pero también de tensiones creativas (n. 8).

Este es el contexto en que debemos tratar de leer hoy las reglas ignacianas, recordando la frase afortunada de X. Alegre: "un texto sin contexto es un pretexto".

4. Tres números más adelante, el decreto mencionará, además, la "jerarquía de verdades" como aportación muy importante. 


\section{Silencios significativos}

Entrando un poco más en los contenidos, ya se ha notado que resulta curioso el que, entre las mil alabanzas que sugiere, no hable Ignacio, por ejemplo, ni de alabar inquisidores, ni de alabar la quema de herejess, ni de alabar sin más al papa o sus nepotismos o sus guerras para conquistar algún condado para sus sobrinos (caso de Julio II). Tampoco habla de alabar obispos o el que éstos residieran fuera de sus diócesis como era práctica muy general entonces, ni de alabar la acumulación de beneficios eclesiásticos en manos de un solo individuo... Es decir: Ignacio aconseja alabar cosas "en las que no estaba el problema", pero calla sobre las que eran radicalmente problemáticas. Varias de esas cosas sobre las que Ignacio calla fueron reformadas más tarde por Trento. Y estos silencios sobre fallos tan frecuentes en su época muestran no sólo que en la Iglesia puede haber cosas no laudables, $\mathrm{ni}$ conformes con el evangelio, sino que resulta un error táctico el que la atención que esos pecados merecían se desvíe hacia otras prácticas quizá menos ilustradas o más ingenuas, pero más secundarias y no tan antievangélicas.

Ignacio, por ejemplo, no quiso que los jesuitas fueran inquisidores, porque "nuestro modo de proceder" debía ser más por la dulzura y la persuasión que por la fuerza. Ni quiso que los jesuitas fueran obispos, porque le parecía que el camino del poder no es el mejor para propagar el evangelio y que la figura social que entonces encamaban los obispos tampoco lo era. Hizo la excepción comprensible de los terrenos de misión. Y no sé si en este punto le hemos sido suficientemente fieles ${ }^{6}$. Finalmente, tampoco hay una recomendación de alabanza incondicional al papa: más bien se conoce un dicho suyo de que el mundo cambiaría con sólo que el papa reformara su persona, su casa-familia y su corte o curia. (El texto dice también junto a la corte, la ciudad de Roma. Pero eso ha perdido vigencia con la pérdida del poder temporal de los papas.)

\section{La autoridad eclesiástica}

Estas claves nos ayudan a comprender no sólo las reglas a las cuales ya hemos aludido, sino las otras que tienen relación más directa con aquellos que detentan en la Iglesia una responsabilidad más "oficial" (sustancialmente la 1, la 10 y la 13).

5. Rechazada por Lutero, quien, por eso, había sido condenado por León X, ya en 1520 .

6. Recuerdo que, cuando Juan Pablo II destituyó al sucesor de Arrupe e impuso un vicario por la fuerza, un padre benemérito que ya murió me dijo que había sido un error de Ignacio el no aceptar jesuitas obispos porque, de haber tenido unos cuantos obispos, nos habríamos defendido mejor y aquello no habría sucedido. Se pueden entender esas palabras desde el dolor del momento; pero no creo que reflejen la mente de san Ignacio, que prefería una Compaña "más indefensa". 


\section{1. "De entrada, sî"}

- La primera regla dice que "depuesto todo juicio, debemos tener ánimo aparejado y pronto para obedecer en todo a la verdadera esposa de Cristo nuestro Señor que es la nuestra santa madre Iglesia jerárquica" (EE 353). Prescindamos ahora de la palabra jerarquía, que no procede del Nuevo Testamento, sino del Pseudodionisio.

El texto de esta regla podría tener dos lecturas: que nuestra madre es la jerarquía eclesiástica, porque ella constituye ese cuerpo de Cristo que es la Iglesia, o que el Cuerpo de Cristo es toda la Iglesia pueblo de Dios, a la cual pertenece como función imprescindible la autoridad, a la cual, por eso, debemos tener ánimo presto para obedecer. Nuestra madre es la comunidad de fieles, que nos ha precedido a lo largo de la historia y nos acompaña hoy. Y a ese "cuerpo de Cristo" pertenecen también otras funciones autorizadas como el llamado "sensus fidelium", la Escritura (a la cual también debe obedecer la autoridad de la Iglesia) o el Espíritu, que sopla donde quiere, y los diversos carismas que también constituyen a la Iglesia (como la palabra profética o esos "vicarios de Cristo" que son los pobres).

Ya en tiempo de Ignacio, pero sobre todo después del Vaticano II, no hay duda de que la verdadera lectura es esta segunda. La primera proviene de una especie de "arrianismo eclesial", que considerarfa que la dimensión divina de la Iglesia se da eliminando de ella toda dimensión humana, y que la jerarquía sola encarna esa dimensión trascendente, excluyendo positivamente a la comunidad eclesial.

Establecido así el carácter de la Iglesia, esta regla dice una gran verdad: "de entrada, sî". De entrada hay que tener el ánimo presto y aparejado para obedecer a la función jerárquica de la Iglesia, que es imprescindible (contra todo espontaneísmo creyente) y que bastantes problemas tiene a veces. Se trata, pues, de un reconocimiento pleno no sólo de la propia eclesialidad, sino de que esa pertenencia eclesial implica la aceptación de la autoridad.

Ignacio hace aquí algo parecido a lo que había hecho Pablo, en el capítulo 13 de la Carta a los Romanos: un reconocimiento claro de la función de la autoridad. Pablo hace ese reconocimiento en un momento de posible amenaza de persecución para la Iglesia (quizá con intenciones apologéticas de defensa de su ministerio, similares a las que Ignacio tiene aquî). Y lo hace, pese a que Pablo pasa hoy por más enemigo del imperio romano de lo que se ha sospechado otras veces?

Pero Pablo no hace más que reconocer la bondad del hecho de la autoridad en la sociedad (con jerga escolástica, diríamos que Pablo defiende el "an sir", no necesariamente el "quid sit" de la autoridad). Defiende su bondad, porque la con-

7. AsI se expresa por ejemplo R. Horsley, en La revolución del reino. 
sidera necesaria y, por tanto, querida por Dios. No entra Pablo aquí en el contenido concreto de algunos ejercicios de esa autoridad. Como también Jesús (en el capítulo 23 de san Mateo), defenderá la misión de las autoridades judías ("hagan lo que les digan"), pero pronunciará un duro alegato contra ellas. De hecho, y volviendo a Pablo, esa misma autoridad para la que él pide obediencia, le asesinaría pocos años después ${ }^{8}:$ ¿significa eso que, en aquel caso concreto, la autoridad imperial "protegía el bien y perseguía al mal" como insinúa Romanos 13, 3? No. Significa simplemente que la autoridad está puesta, de hecho, para esa tarea de perseguir al mal y proteger al bien (y los ejemplos siguientes que aduce Pablo: paguen los impuestos y paguen las deudas, lo muestran claramente). Cuando esa autoridad pida la adoración del César como Señor, cesará ese "ánimo aparejado y pronto", y los cristianos, lectores de la carta paulina, irán hasta el patíbulo por desobedecer.

Por eso también, otro escrito posterior del Nuevo Testamento, el Apocalipsis, atendiendo no al hecho en sí, sino a las actuaciones concretas de las autoridades, llamará "Babilonia" a la misma autoridad que Pablo consideraba como "puesta por Dios". Y esa práctica ha seguido vigente en la Iglesia, cuando el ministerio jerárquico se apartó de la voluntad divina?.

Situada así, no se piense que con ello hemos desactivado esta primera regla. Al contrario. No se tiene el verdadero sentir en la Iglesia, cuando la disensión o el conflicto no nos duelen a nosotros tanto como a la autoridad, cuando el necesario pro-fetismo se convierte en pro-tagonismo (y se pasa de "hablar-ante": de una palabra pública, a "pelear-ante" de manera exhibicionista). Ni se tiene ese verdadero sentir cuando, a la hora de levantar la voz, no nos encontramos divididos como el profeta Jeremías: que no podía callar, porque la palabra de Dios le había seducido y le quemaba, pero se lamentaba, porque esa palabra era para él motivo de burlas y de mil problemas. La innegable disensión que hoy se da en un amplio sector del pueblo de Dios, respecto de la jerarquía, puede ser justificada, pero debería examinarse ante Dios de cuanto acabamos de decir.

\subsection{Mentira, no}

Este tema de la palabra pública está en la Iglesia enormemente condicionado por las circunstancias. Ignacio parece sospechar de ella en la regla 10, pero la razón que da sitúa esa sospecha en un contexto que no es el nuestro: para no engendrar "más murmuración y escándalo que provecho en el pueblo menudo"

8. Nerón había subido al trono el 54. La Carta a los Romanos es más o menos del 576 58. Y el incendio de Roma, con la posterior persecución a los cristianos, en la que murió Pablo, fue el 64.

9. Ver los impresionantes textos que recojo en La libertad de palabra en la Iglesia y la reología, casi todos ellos de santos o de jerarqulas eclesiásticas. 
(EE 362). Esta razón refleja una situación confesional, donde la Iglesia está prácticamente identificada con la sociedad civil y donde no existen los medios de comunicación propios de una sociedad laica y democrática. En este otro tipo de sociedades puede ocurrir que al pueblo menudo le escandalice y le desaproveche más el que gentes de Iglesia no reconozcan, o den la sensación de esconder y de negar, fallos que han sido ya hechos públicos por otro camino. Incluso en una sociedad como la medieval, en momentos en que los fallos de la jerarquía eran mucho más ostentosos y públicos, san Bernardo o santa Catalina de Siena se vieron llamados a denunciarlos públicamente y, precisamente, en provecho del pueblo menudo. La misma autoridad eclesística ha reconocido y enseñado la legitimidad (y la necesidad) de esas conductas (como muestra la obra citada, en la nota anterior $)^{10}$.

\subsection{Ojos purificados}

Relacionada con éstas hay otra regla (la 13: EE 365) que habla también de actitudes más que de actos (como hacían las comentadas anteriormente): "debemos siempre tener, para en todo acertar, que lo blanco que yo veo creer que es negro, si la iglesia jerárquica así lo determina". Es ya tópico contraponer esta regla con la afirmación de Erasmo: "lo blanco nunca será negro aunque así fuese definido por el pontifice de Roma", olvidando a veces que Erasmo añade: "y por eso sé que nunca hará esa definición". Las diferencias son claras: Erasmo habla de lo que es blanco; san Ignacio de lo que yo veo. Quizá por eso no dice que "debemos creer", sino que debemos "tener", dejando aqui cortada la frase que parece pedir una "disposición a", para no quedar incompleta.

Se trataŕa por tanto de una disposición muy querida a san Ignacio: la desconfianza respecto de uno mismo, que le lleva a tantos discernimientos y consultas, y que debe actuarse de manera especial, en los casos de conflicto con la autoridad. Pero Ignacio sabe también, y reconoce en otros lugares, que, a veces, lo blanco que yo veo puede ser rotundamente blanco, si mi visión está del todo purificada. Sabe que, a veces, puede forzar al súbdito "la evidencia de la verdad conocida" y que, por eso, no siempre "la devota voluntad puede inclinar al entendimiento" (con expresiones tomadas del documento más fuerte y citado de san Ignacio a favor de la obediencia). No entra aquí a discernir cuándo esa

10. Y esto es lo que percibió la CG 34, cuando escribe: "si la Iglesia es atacada o difamada por los medios de comunicación, no podemos limitarnos a una condena genérica de tales abusos. Debemos saltar al campo de las comunicaciones sociales y defender la verdad, reconociendo al mismo tiempo honradamente los conflictos y polarizaciones existentes en el interior de la Iglesia. Aunque deberfamos hacerlo sin exacerbar tensiones ni debilitar la autoridad, no podemos soslayar asuntos que, por ser noticia, los medios de comunicación presentarán en cualquier caso" (n. 25). Con otras palabras: la verdad no se defiende con el silencio, sino con la verdad misma. 
"evidencia de la verdad conocida" podrá pasar desde el entendimiento a lo que él llamaba "obediencia de voluntad" (o voluntad de obedecer), o incluso afectará a la misma ejecución de lo mandado. Como tampoco describe aquí cuáles pueden ser las formas de esas "evidencias" más fuertes (objeción de conciencia por ejemplo, o daño del pueblo creyente). Esa será una casuística ulterior. Pero que esa casuística puede presentarse lo muestra el mismo santo cuando, en una de las decisiones que más le costaron (la de aceptar ser dirigente del grupo que con él estaba naciendo) y después de mucho pensar, deterninó consultarlo a su confesor, "haciendo oblación que de la sentencia de su confesor un punto no saldría, aunque el papa le mandase lo contrario"'I.

Como ya señalé otra vez, se trata por tanto de "una aceptación incondicional de la función de la autoridad, más allá de las eventuales coincidencias personales y aun en estructuras autoritarias más que discutibles". Y la razón que da esta regla 13 tiene también su exégesis en la vida misma de san Ignacio: "entre Cristo nuestro Señor esposo y la Iglesia su esposa, es el mismo espíritu que nos gobiema y rige". El Espiritu es el mismo, pero al Espíritu hay que darle la libertad para "soplar donde quiera" y, a veces, puede soplar el mismo Espíritu, en direcciones aparenternente contrarias, que él ya se encargará de armonizar.

Esto es lo que vivió san Ignacio, por ejemplo, cuando el papa quiso nombrar obispo a Francisco de Borja, creando una gran turbación al fundador, que estaba convencido de que Dios le había llevado a rechazar obispados para los jesuitas. Tras cuatro días de oración, en los que al principio reconoce que no se sentía con libertad de espíritu para estorbarlo, escribió a Borja que "finalmente yo me hallé en la sólita ocasión y después acá siempre [= en aquel momento y desde entonces] con un juicio tan pleno y con una voluntad tan suave y tan libre para estorbar lo que en mí fuese, delante del papa y cardenales que, si no lo hiciera, yo tuviera y tengo por cosa cierta que a Dios nuestro Señor no daría buena cuenta de mi, antes enteramente mala... He tenido y tengo que, siendo voluntad divina que yo en esto me pusiese [aun] poniéndose otros al contrario... no habría contradicción alguna pudiendo el mismo espiritu divino moverme a mí a esto por unas razones y a otros al contrario por otras"'t2. He aquí una primera formulación avant lettre de lo que después se ha llamado objeción de conciencia.

\section{Una eclesiología mínima de la Iglesia "militante"}

No cabe suponer que en este y algún otro caso parecido, Ignacio incumpliera sus propias reglas "para el verdadero sentido que en la iglesia militante debemos tener". Se trata simplemente de que la Iglesia es militante y no todavía triunfante. $\mathrm{Y}$ esto quiere decir que es, a la vez, santa y pecadora ("casta y meretriz"), fraterna

11. Ver Obras completas (edición de la BAC, 1963), p. 290.

12. Carta a Francisco de Borja del 5 de junio de 1522. En op. cir. p. 51. 
y conflictiva. Iglesia militante significa Iglesia que lucha: contra enemigos de fuera, contra dificultades no previstas y contra divisiones internas. Esos tres pos- tulados aparecen constantemente en el libro de los Hechos. Y me gusta decir que más que "hechos de los Apóstoles" debería titularse "dificultades de los Apóstoles". Será verdad que Lucas edulcora muchas veces esas situaciones difíciles; pero también sucede que la realidad se le va filtrando, a través de su texto edificante. Los creyentes "tenían un solo corazón y una sola alma" $(4,32)$; pero dos capítulos después, comienzan a aparecer las disensiones. $Y$ otra disonancia que todavía me hace a mí más gracia: tras decir (en 9, 30) que a Pablo lo quisieron matar y los hermanos tuvieron que bajarlo a Cesarea, añade en el verso siguiente: "la Iglesia gozaba de paz en toda Judea". Esa es la paz de la Iglesia militante: no la paz por ausencia de dificultades, sino en medio de ellas. Y esto olvidan muchos eclesiásticos que, en pleno siglo XXI, creen hacer bien, negando la realidad y presentando una imagen "celestial" de la Iglesia terrestre. No es así como la Iglesia militante tiene algo de triunfante.

A ese carácter militante de la Iglesia pertenece también el que la verdad a conservar sólo pueda ser accesible "como en un espejo y confusamente" (1Cor 13,12 ). Ello hace que la necesidad de defender y conservar lo recibido, vaya acompañada de la obligación de distinguirlo de "las formas" en que lo hemos recibido, o de distinguir lo que se nos entregó de los envoltorios (iimprescindibles!) en que se nos entrego. O con otras palabras: distinguir la Tradición de las tradiciones. La historia de la Iglesia suministra en este punto dos lecciones importantes: a) que la mayoría de la gente que apela a "la Tradición" está tratando, en realidad, de defender "al siglo pasado" mucho más que a lo originario de la Iglesia ${ }^{13}, \mathrm{Y}$ b) que, como ocurrió cuando la crisis arriana, esas tradiciones que deforman la Tradición, pueden, en algún momento, ser dominantes y revestidas de autoridad en la Iglesia ${ }^{14}$.

Precisamente por eso, he insinuado hace un momento que lo que debemos buscar no es la literalidad de lo que Ignacio dijo entonces, sino lo que nos diría hoy. Sabemos que los evangelistas hicieron esto, en más de una ocasión, adaptando palabras y recuerdos de Jesús a lo que significaban en aquellas comunidades a las que escribían. $\mathrm{Y}$ el evangelio más tardío canonizó este modo de

13. Este fue el error fundamental del cisma lefebvriano.

14. Aludiendo a esa crisis, escribe un comentarista de estas reglas: "el mismos Vicente de Lerins comprendió que los arrianos, en el apogeo de su partido, hubiesen podido aplicar con éxito tal principio contra Atanasio y sus seguidores, que entonces aparecían como unos innovadores radicales en lucha para afirmar una extraña terminología contra los tradicionalistas" (G. O'Collins en C.I.S. $n^{\circ} 44$, p. 106). El principio a que alude este texto es aquel canon famoso de san Vicente de Lerins: "es verdaderamente católico lo que se ha creído siempre, en todas partes y por todos como parte del Evangelio de Cristo". 
proceder, cuando asigna al Espíritu la tarea no sólo de recordar, sino de enseñar y llevar a plenitud la verdad de Jesús, hecha visible en, pero no limitada por, sus condiciones historicas.

\section{Vuelta a la autoridad}

Visto todo lo anterior, creo que no cabe interpretar esta regla 13, en el sentido de lo que más tarde se llamó en teología moral un "tuciorismo absoluto" (que además fue condenado por la misma autoridad eclesiástica, $c f r$. DH 2303. Pero incluso ni siquiera cabe interpretarla en contra del llamado "probabilismo", o licitud de defender una opinión moral con sólo que fuera sólidamente probable, aunque no fuera la más probable (o probabiliorismo). A pesar de los esfuerzos del General Tirso González, por imponer el probabiliorismo a toda la orden, la Compañía de Jesús defendió siempre la primera opción que, en algún momento, fue contraria a la del papa. Y la tradición moral enseñaba que entre los datos para considerar como sólidamente probable una sentencia están no sólo los argumentos intrínsecos, sino las autoridades extrínsecas que la defienden, de modo que "lo que yo veo" se convierte aquí en lo que nosotros vemos. Y este nosotros puede convertir a la opinión en sólidamente probable ${ }^{15}$.

Y la razón de esto es que era una convicción muy ignaciana el que la autoridad no nos quita la capacidad de razonar: en los Ejercicios aplica este principio incluso a la autoridad de la sagrada Escritura ("la Escritura supone que tenemos entendimiento", n. 299) para afirmar algo que no consta en el texto sagrado. Y este principio era para él tan serio que lo aplicó incluso en contra de sí mismo, cuando era autoridad. Así, reprendió a un administrador que habfa seguido al pie de la letra una orden suya discutible: "aunque yo diga eso ¿no habéis vos de tener discreción?". Y alabó a un súbdito que, tras madura reflexión y oración, le habia desobedecido, creyendo que si el santo hubiese conocido el caso de cerca, le habría ordenado hacer lo que hizo: "el hombre comunica las ordenes pero Dios da la discreción. Quiero que, en las demás cosas, actuéis sin escrúpulo - sin que obsten las reglas y las ordenaciones - según juzguéis por las circunstancias que se debe actuar"16. Este Ignacio no puede estar en contradicción con el que había escrito las reglas para sentir rectamente en la Iglesia. Y ello prueba, en mi opinión, la validez de las claves hermenéuticas que propusimos.

15. Un ejemplo actual de esta posición puede ser la cuestión del uso del preservativo, en determinados casos, como mal menor para prevenir el SIDA. La respuesta afirmativa me parece hoy, en estricta teología moral, sólidamente probable.

16. Ver Fontes narrativi... II, 482 y III, 434. Para contextuar más todas estas citas, remito a mi estudio: "La fidelidad como memoria de libertad. Ignacio de Loyola ante el poder", en Memoria de Jesús. Memoria del pueblo, Santander 1984, pp. 33-98. 


\section{Balance}

- En resumen, estas reglas podrían reducirse a dos puntos: una actitud y unos actos. Una actitud de "ánimo pronto y dispuesto" para con la autoridad eclesiástica. Y unos actos para con la "religiosidad popular", que se reducen casi sólo a "alabar" sus diversas prácticas, y que hoy (en un contexto menos vidrioso) podríamos reformular como aceptación.

Este sería, ciertamente, un "recto sentir" en la Iglesia. Y este recto sentir no excluye, en ninguno de esos dos casos, ni la necesidad, ni los compromisos de reforma de la Iglesia: lo que busca es que esos esfuerzos actúen desde el interior y no como una imposición desde el exterior.

Cartas de jesuitas posteriores como Nadal, Laínez y Pedro Canisio, muestran su empeño por la reforma de la curia romana. Porque, como escribió el primero de ellos al segundo, "los de la Compañía son papistas en lo que deben serlo y no en lo demás, y sólo con el intento de la divina gloria y bien común"'17. S6lo con ese intento.

En definitiva pues, lo que cree san Ignacio es que el reformador auténtico es aquel a quien se exige mayor eclesialidad. Porque en él (echando mano de un conocido título de Pedro Casaldáliga -En rebelde fidelidad - ), la fidelidad es lo sustantivo, aunque circunstancias históricas puedan obligar a que la acompañe un adjetivo que parece estar en difícil dialéctica con ella.

\section{Y en conclusión}

Si nuestro análisis ha sido válido, se comprende la razón que asiste a la Congregación General 34, cuando escribe, en su decreto varias veces citado:

Nuestra respuesta [a las divisiones y situación actual de la Iglesia] puede causar tensiones con algunas autoridades eclesiásticas. A pesar $-y$ precisamente por causa - de nuestro sincero deseo de ser fieles al Magisterio y a la jerarquía, puede haber momentos en los que nos sintamos justificados, incluso obligados, para hablar de una manera que no siempre nos granjee la aprobación general y hasta pueda conducirnos a sanciones dolorosas para la Compañia y obstaculizadoras de nuestro trabajo. Obrar así no equivale a desobediencia ni rebeldía (NB. Los subrayados son míos).

Y porque en la Iglesia no es posible sentir rectamente con "una mentalidad contraria a la de Jesús" ( $c f r$. Fil 2, 5), por eso podemos, y debemos orar, proclamar y trabajar para que ella sea de veras la Iglesia de los pobres ( $f f r$ Lc 6, 20); para que tenga lugar una profunda reforma de papado y jerarquía que los lleve a "no ser como los poderes de este mundo" ( $f f r$ L L 22, 26), y por la unión de todos los cristianos (cfr. Jn 17, 21). Esta triple tarea nos la impone también el "verdadero sentir que en la Iglesia militante debemos tener".

17. En abril de 1563. Monumenta historica societatis lesu 2, 263. 